Daniel Eduardo Agudelo Torres

Jose Navarro-Martinez

Maria Galiana-Ivars

Carmelo Alarcon Martinez

\section{Comments on Cecconi et al.: Consensus on circulatory shock and hemodynamic monitoring. Task force of the European Society of Intensive Care Medicine}

Accepted: 26 November 2014

Published online: 5 December 2014

(C) Springer-Verlag Berlin Heidelberg and ESICM 2014

Dear Editor,

We read the valuable and interesting

"Consensus on circulatory shock and hemodynamic monitoring" by Cecconi et al. [1]. We remarked the importance of their work, which provides us with recommendations for the ideal approach for patients with this condition.

Understanding that one of the objectives of their publication is to develop guidelines for adequate monitoring of patients in shock, we noted that they did not provide a recommendation for the ideal monitoring site for invasive arterial blood pressure (ABP).

Knowing that the accuracy of ABP monitoring is crucial in treating shock patients and some studies have repeatedly demonstrated inconsistencies between femoral and radial access, some research has proved that radial $\mathrm{ABP}$ monitoring significantly underestimates femoral ABP during vasopressor therapy in critically ill patients and suggested that inserting a femoral line substantially reduces the infusion rate of vasoactive drugs [2].

Another study confirms a high prevalence of differences between MAP measurements at the radial and femoral sites in critically ill patients who require treatment with vasoactive medications, which results in changes in the clinical management, such as the vasopressor dose or fluid administration [3].

A more recent study showed large discrepancies in MAP measured at the radial site frequently underestimates central pressure in septic shock patients receiving high-dose norepinephrine (NE) therapy. These results suggest that, in patients with marginally maintained MAP measured at the radial artery under high doses of NE therapy, MAP measurement at the femoral artery may be necessary to avoid a potentially harmful fluid challenge or dose increase of vasopressors [4].

For us this matter has significant value because the radial artery continues to be the most common cannulation site even in shock patients, with the assumption that this peripheral pressure is an accurate surrogate for central pressure. This premise may be flawed in the abnormal hemodynamic state of critical illness. The other reason for the preference is the well-documented low complication rates. However, recent studies conclude that incidence rates for major complications such as permanent ischemic damage, sepsis and pseudoaneurysm formation are low and similar for the radial, femoral and axillary arteries. They occur in less than $1 \%$ of cases [5].

If we consider this evidence our patients will benefit from taking a stand about what is the ideal monitoring site for $\mathrm{ABP}$ in patients with circulatory shock.

\section{References}

1. Cecconi M, De Backer D, Antonelli M, Beale R, Bakker J, Hofer C, Jaeschke R, Mebazaa A, Pinsky MR, Teboul JL, Vincent JL, Rhodes A (2014) Consensus on circulatory shock and hemodynamic monitoring. Task force of the European Society of Intensive Care Medicine. Intensiv Care Med 40(12):1795-1815. doi:10.1007/s00134-014-3525-Z

2. Dorman T, Breslow MJ, Lipsett PA, Rosenberg JM, Balser JR, Almog Y, Rosenfeld BA (1998) Radial artery pressure monitoring underestimates central arterial pressure during vasopressor therapy in critically ill surgical patients. Crit Care Med 26(10):1646-1649

3. Galuccio ST, Chapman MJ, Finnis ME (2009) Femoral-radial arterial pressure gradients in critically ill patients. Crit Care Resusc 11(1):34-38

4. Kim WY, Jun JH, Huh JW, Hong SB, Lim CM, Koh Y (2013) Radial to femoral arterial blood pressure differences in septic shock patients receiving high-dose norepinephrine therapy. Shock 40(6):527-531

5. Scheer B, Perel A, Pfeiffer UJ (2002) Clinical review: complications and risk factors of peripheral arterial catheters used for haemodynamic monitoring in anaesthesia and intensive care medicine. Crit Care 6(3):199-204

D. E. Agudelo Torres ( $\bullet$ )

J. Navarro-Martinez · M. Galiana-Ivars · C. A. Martinez

Hospital General, Universitari d'Alacant,

Alicante, Spain

e-mail: agudelodaniel@hotmail.com 